\title{
Protocol for the Preparation of Arabidopsis Meiotic Chromosome Spreads and Fluorescent in situ Hybridization
}

Pablo Bolaños-Villegas ${ }^{1}$, Xiaohui Yang ${ }^{2}$, Christopher A. Makaroff ${ }^{2}$ and Guang-Yuh Jauh ${ }^{1^{*}}$

${ }^{1}$ Academia Sinica, Institute of Plant and Molecular Biology, Taipei, Taiwan; ${ }^{2}$ Department of Chemistry and Biochemistry, Miami University, Oxford, OH, USA

*For correspondence: jauh@gate.sinica.edu.tw

[Abstract] This protocol is a more detailed version of previous protocols (Yang et al., 2011; Bolaños-Villegas et al., 2013) developed for the examination of meiotic chromosome spreads. Meiotic chromosome spreads are useful to determine the presence of defects in chromosome pairing and segregation. The protocol also describes how to perform fluorescent in situ hybridization experiments with a centromere probe used to label chromosomes.

\section{Materials and Reagents}

1. Inflorescences from young, healthy Arabidopsis thaliana plants

2. Agar plates, with $1 / 2 x$ Murashige and Skoog solid medium

3. Pectolyase (Sigma-Aldrich, catalog number: P3026)

4. Cellulase (Sigma-Aldrich, catalog number: C1184)

5. $\beta$-glucoronidase (Roche Diagnostics, catalog number: 03707598001)

6. Sucrose (Affymetrix, catalog number: 21938)

7. Ethanol (EMD Millipore, catalog number: 1085430250)

8. Chloroform (EMD Millipore, catalog number: 102442)

9. Glacial acetic acid (EMD Millipore, catalog number: 100063)

10. Citric acid anhydrous (Affymetrix, catalog number: 13729)

11. Sodium citrate dihydrate (Affymetrix, catalog number: 13735)

12. Formamide (Sigma-Aldrich, catalog number: F9037)

13. Saline-sodium citrate (SSC) (Sigma-Aldrich, catalog number: S0902)

14. Dextran sulfate (Sigma-Aldrich, catalog number: 42867)

15. Salmon sperm (Life Technologies, catalog number: 15632-011)

16. VECTASHIELD ${ }^{\circledR}$ mounting medium with DAPI $(10 \mathrm{ml})$ (Vector Laboratories, catalog number: $\mathrm{H}-1400$ )

17. Fluorescein High-Prime labeling kit (Roche Diagnostics, catalog number: 11585622910)

18. pAL1 centromere probe (ABRC, catalog number: CD3-16)

19. Taq DNA polymerase with standard Taq buffer (New England Biolabs, catalog number: 
M0273S)

20. QIAquick Gel Extraction Kit (kit for purification of DNA from gels) (QIAGEN, catalog number: 28704)

21. Gel Pilot $1 \mathrm{~Kb}$ Ladder (molecular weight marker for DNA) (QIAGEN, catalog number: 239085)

22. Agarose for electrophoresis (Bio-Rad Laboratories, catalog number: BR 161-3100)

23. Carnoy's solution (see Recipes)

24. $10 \mathrm{mM}$ Sodium citrate buffer (see Recipes)

25. Enzyme digestion buffer (see Recipes)

26. FISH Buffer (see Recipes)

27. 10x PBS (see Recipes)

28. 20x SSC (see Recipes)

\section{Equipment}

1. Hypodermic needles and syringe (Terumo Medical Corporation, model: $26 \mathrm{G} \times 1 / 2$ ", catalog number: NN-2613R)

2. Tweezers (Dumont)

3. Poly-Prep ${ }^{\circledR}$ poly-L-lysine coated slides (Sigma-Aldrich, catalog number: P0425-72EA)

4. Nunc $^{\circledR}$ Lab-Tek $^{\circledR}$ II slides (Thermo Fisher Scientific, catalog number: 154453)

5. Coverslips (Matsunami Glass, catalog number: C218181)

6. Hybridisation oven OV1 (Biometra, catalog number: 052-090)

7. Thermal cycler (Biometra, catalog number: 050-551)

8. Dry block (Thermo Fisher Scientific, Reacti-Therm ${ }^{\circledR}$ )

9. $-86{ }^{\circ} \mathrm{C}$ refrigerator (Thermo Fisher Scientific, model: Forma ${ }^{\circledR} 88000$ )

10. Frigidaire $-20^{\circ} \mathrm{C}$ refrigerator (Amazon, model: FCFS201LFB)

11. Fluorescence microscope

12. Coplin staining jars (Thermo Fisher Scientific, catalog number: 107)

13. Rubbermaid LunchBlox ${ }^{\circledR}$ food containers

14. Super Pap Pen' liquid blocker pen (Electron Microscopy Sciences, catalog number: 71310) (optional)

\section{Procedure}

A. Preparation of Arabidopsis meiotic chromosome spreads

Note: The most important aspect of this experiment is to collect flower buds at the right stage to isolate anthers that contain male meiocytes. Typically flower buds come in racemes, and 
only 3-4 are usable. Their size cannot exceed $1 / 4$ of the length of the mouth of a Terumo ${ }^{\circledR} 26 \mathrm{G}$ $x 1 / 2$ " hypodermic needle (approx. $1 \mathrm{~mm}$ ). Anthers should be green. In order to prepare a single slide 5-10 flower buds are required.

1. Prior to anther collection and fixation remove the enzyme digestion solution from the refrigerator and allow it to thaw on ice. In the meantime set a hybridization oven at $37^{\circ} \mathrm{C}$, and prepare a lunch box in which the bottom is covered by moist tissues. On the bottom of the lunch box place a rack for PCR tubes, and place the slides on top to avoid direct contact with the wet tissues. Digestion of the anthers allows free meiocytes to be released onto slides where they can be stained and observed under the microscope.

2. Racemes are placed first on 1/2x Murashige and Skoog agar plates. Flower buds are excised with tweezers and then placed in a drop of double distilled water $(20 \mu \mathrm{l})$ in a Lab-Tek ${ }^{\circledR}$ II slide. Lab-Tek ${ }^{\circledR}$ || slides are perfect for this experiment since their coating keeps water drops in place, something regular poly-L-lysine slides cannot do.

3. To remove water or any other solution, press the mouth of the needle against the slide, and lift the piston of the syringe slowly (the piston can be lifted slightly before placing the syringe against the slide). Choose an area away from the buds. If possible use the tweezers to stretch the droplet away from the buds.

4. Once all flower buds are placed on water, work can begin. Individual flower buds are moved onto a dry area within the slide. After $10 \mathrm{sec}$ the buds mostly dry out and can be dissected at ease. For dissection two tools are used: a tweezer and two hypodermic needles $(26 \mathrm{G} \times 1 / 2$ "). Flower buds are placed horizontally and cut at the base with the needles. This allows for quick removal of the petals. Once petals are removed the anthers can be moved individually into a drop of water with the aid of the needles. It is important to maintain the needles dry to allow easy manipulation of the remaining anthers. Yellow anthers are not meiotic anthers and should not be used at all. Anthers must remain moist at all times.

5. Once anthers are all placed together, water is removed, leaving only $5 \mu \mathrm{l}$. In this way all buds can be further aggregated with the needle. Then add Carnoy's fixative $20 \mu \mathrm{l}$ for 20 min, and replenish every 5 min to avoid evaporation (as an option the Super Pap Pen' liquid blocker pen can be used to better contain the Carnoy's fixative). Carnoy's fixative contains no formaldehyde, gluteraldehyde or chloroform, therefore it has little toxicity and allows subsequent ease of manipulation. After $20 \mathrm{~min}$ have the fixative removed but leave at least $5 \mu \mathrm{l}$. Aggregate the anthers. Then quickly add water, and have it quickly removed (but never totally, leave $5 \mu \mathrm{l}$ ). Then change water two more times ( 5 min each).

6. Add citrate buffer $(20 \mu \mathrm{l})$. This buffer is used to prepare anthers for enzymatic digestion.

7. After removal of citrate buffer add $20-40 \mu \mathrm{l}$ of enzyme solution to the slide, place a Lab-Tek $^{\circledast}$ II plastic cap on top of the slide (each slide comes with a cap), place the slides 
inside the lunch box, close it well, and have it placed inside the hybridization oven. Allow digestion of the buds for $2 \mathrm{~h}$ at $37^{\circ} \mathrm{C}$. Once digestion is finished, remove the slides, and remove most of the solution (leave $5 \mu \mathrm{l}$ ). Then quickly add $20 \mu \mathrm{l}$ of citrate buffer, and have it quickly removed (never totally, leave $5 \mu \mathrm{l}$ ), then change the citrate buffer two more times ( 5 min each) and leave only $10 \mu \mathrm{l}$ on the slide. Remove the citrate buffer slowly and carefully. If citrate is removed too quickly most anthers will be removed as well and the slides may contain few or no meiotic spreads.

8. At this point use the needle, or the tweezers to squeeze the anthers. This allows the release of free meiocytes onto the slide. Do it slowly, for about $10 \mathrm{~min}$. It is important to squeeze slowly and carefully; otherwise the anthers will adhere to each other. At this point the solution will turn turbid, which is normal. Add buffer if needed.

9. Add $20 \mu \mathrm{l}$ of $60 \%$ acetic acid, and mix slowly. The solution will turn transparent. Do not allow to evaporate. Acetic acid causes meiocytes to swell, thereby improving the quality of the final chromosome spreads. Transfer $5 \mu \mathrm{l}$ of the resulting cells suspension to four different poly-L-lysine slides. Place a glass coverslip on top, but before placing it carefully misalign the coverslip by 45 degrees to either side to allow protrusion of one corner. Fold a piece of paper tissue and place a slide inside, then press firmly from above with your thumb. It is very important to keep your thumb in place to prevent displacement of the coverslip. Application of pressure allows bursting of the cells and removal of cytoplasm, while the use of paper tissue prevents the slide from breaking while applying pressure from above.

10. Move the slides to a $-80{ }^{\circ} \mathrm{C}$ refrigerator, and leave them there for at least $10 \mathrm{~min}$. Then take them out quickly and remove the coverslip with the help of a razor. Allow the slides to air dry at room temperature.

11. Once the slides are dry add 5-30 $\mu$ of DAPI solution (vectashield with mounting medium for instance) to one of the 4 slides and cover with a new coverslip. Observe one slide under a fluorescence microscope to confirm whether the slide contains good meiotic chromosome spreads, if so the remaining slides can be used for FISH experiments. Meiotic stages can be identified using Figure 1 as a template (previously unpublished). You may seal the edges of the coverslip with regular nail polisher for short-term storage in the dark. Vectashield contains a mounting medium that allows for short term storage. 

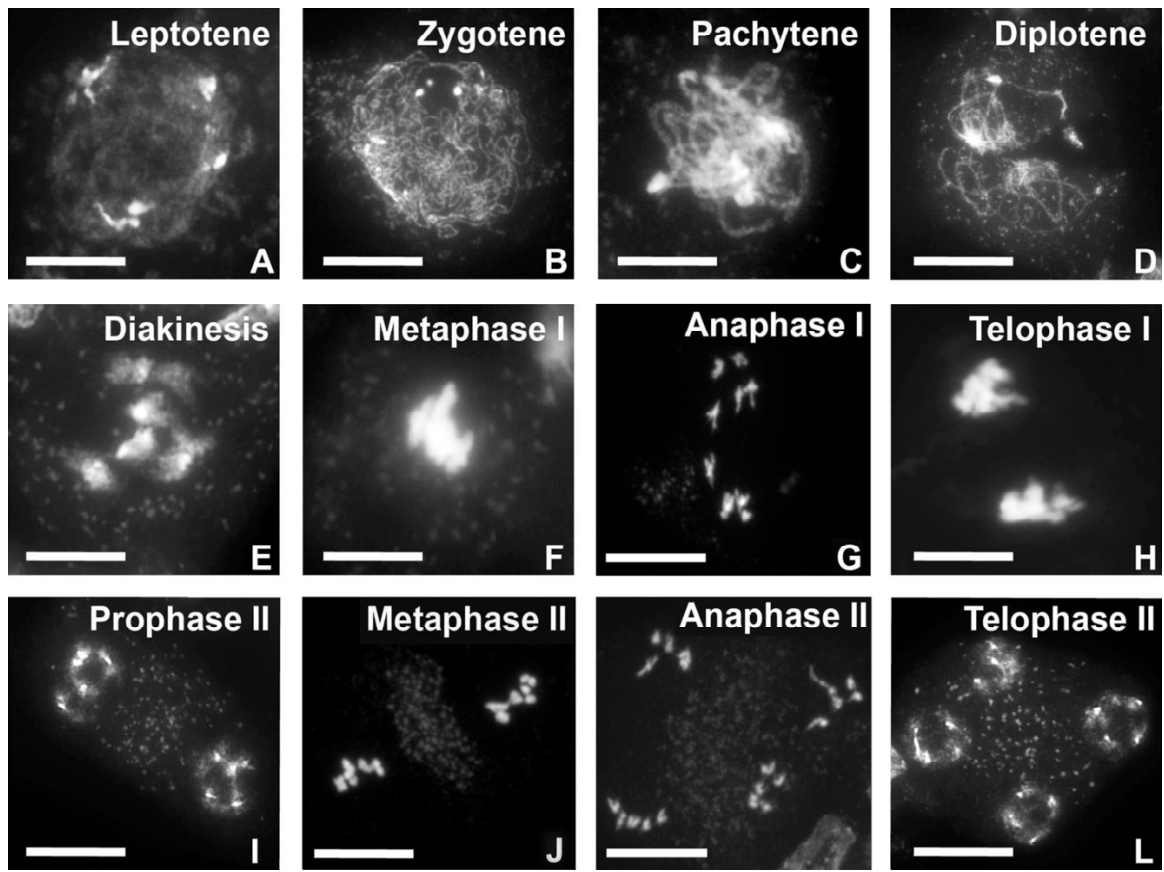

Figure 1. Stages of male meiosis in Arabidopsis as visualized by DAPI staining. In the wild type five bivalents are always observed during metaphase-I. Scale bar: A-D, 20 $\mu \mathrm{m} ; \mathrm{E}, \mathrm{F}, \mathrm{H}, 5 \mu \mathrm{m}$; G, I-L, $10 \mu \mathrm{m}$

\section{B. FISH (fluorescence in situ hybridization)}

12. Prepare $70 \%$ formamide in $2 \times$ SSC $(700 \mu \mathrm{l}$ formamide, $100 \mu \mathrm{l} 2 \times$ SSC and $100 \mu \mathrm{l}$ distilled water). Add $50 \mu \mathrm{l}$ to each slide, place a coverslip on top and place the slides on a hot dry block set at $80^{\circ} \mathrm{C}$. After $30 \mathrm{sec}$ you may either a) dip the slide on water inside a Coplin jar to dislodge the coverslip, or b) apply $20 \mu \mathrm{l}$ of water to lift the coverslip. Then place the slides in a Coplin jar filled with $200 \mathrm{ml}$ of $70 \%, 90 \%$ and $100 \%$ ethanol, for 5 min each. Please notice that all ethanol solutions must be cooled in advance at $-20^{\circ} \mathrm{C}$. After the bath series is finished allow the slides to air dry at room temperature.

13. In the meantime prepare the pAL1 centromere probe (for this step you require a fully labeled probe). Concentration of probe: $20-30 \mathrm{ng} / \mu \mathrm{l}$. Dissolve $1.5 \mu \mathrm{l}$ in $13.5 \mu \mathrm{l}$ of FISH buffer (for one slide), for a final FISH probe concentration of approximately $2-3 \mathrm{ng} / \mu \mathrm{l}$ (see Notes). Incubate the probe at $80^{\circ} \mathrm{C}$ for 5-10 min to denature DNA. Spin shortly afterwards with a microcentrifuge (at approximately $10,000 \mathrm{rpm}$ ), at room temperature. Then quickly place the FISH probe mix on ice for at least $5 \mathrm{~min}$.

14. Add $15 \mu \mathrm{l}$ of FISH probe onto each slide. Cover with a coverslip and incubate the slides on the lunch box overnight at $37^{\circ} \mathrm{C}$. The bottom of the box should contain wet paper tissues to maintain a high humidity and avoid dessication of the FISH probe.

15. Next morning dip the slides on water to remove the coverslip, and then place the slides on 
a Coplin jar. Wash with $200 \mathrm{ml}$ 2x SSC for $10 \mathrm{~min}$, four times.

16. You can check the condition of the slides at this point by taking one and have it stained with DAPI.

17. Wash the slides on $200 \mathrm{ml}$ hot $2 x \operatorname{SSC}\left(45^{\circ} \mathrm{C}\right)$ for $10 \mathrm{~min}$, and after that in $200 \mathrm{ml} 1 \mathrm{x}$ PBS for 5 min. Washing with PBS is not considered essential and can be skipped.

18. Add DAPI $(5 \mu \mathrm{l})$ while the sample is wet. Cover with a coverslip and observe. Results can be compared with Figure 2 (previously unpublished).

19. If for some reason cells are washed away, you can wash the cells on 2x SSC for 15 min once and then directly stain with DAPI.

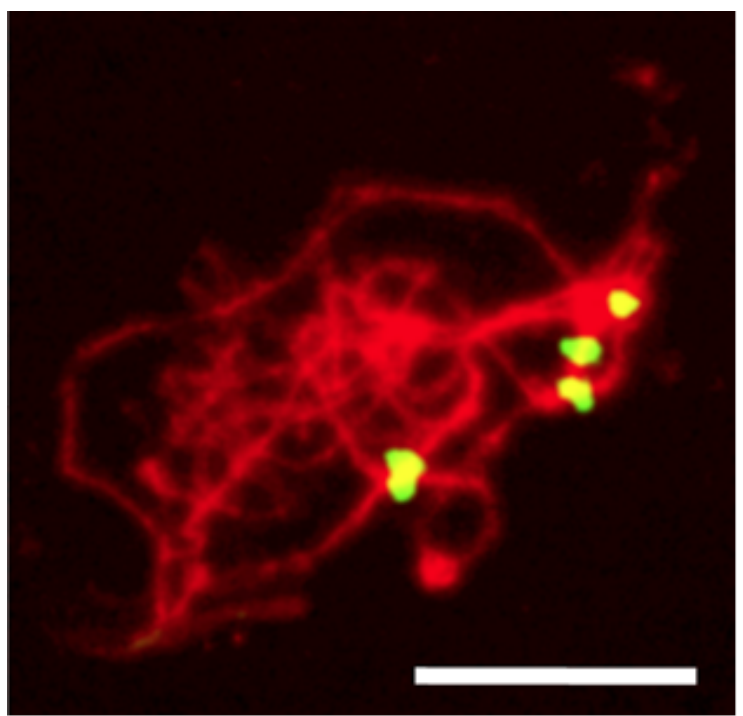

Figure 2. Arabidopsis male meiotic spread (zygotene stage) hybridized to the pAL1 centromeric 180 bp repeat (yellow) and counterstained with DAPI (red, pseudocolor). The number of centromere signals (4) roughly corresponds to the actual number of bivalents (5). Scale bar: $10 \mu \mathrm{m}$

\section{Notes}

1. How to prepare a centromere probe

In order to prepare the centromere probe, PCR must be performed with specific primers (M13 forward and reverse). These two primers are required for the amplification of the Arabidopsis 180 bp centromeric repeat using the centromere-containing plasmid, pAL1 as a template. The primers are as follows:

M13-Forward: 5'-GTAAAACGACGGCCAG-3'

M13-Reverse: 5'-CAGGAAACAGCTATGAC-3'

Ordinarily, the pAL1plasmid is diluted1/100x for PCR and the resulting product is labeled 
for $8 \mathrm{~h}$ with the Fluorescein High-Prime labeling kit. Please read the manufacturer's instructions carefully.

\section{$\underline{\text { Recipes }}$}

1. Carnoy's solution (v/v)

95\% ethanol, chloroform and glacial acetic acid (6:3:1)

2. $1 \mathrm{~L} 10 \mathrm{mM}$ Sodium citrate buffer

$1.045 \mathrm{~g}$ citric acid anhydrous (MW = 192.12)

1.479 sodium citrate dihydrate $(\mathrm{MW}=294.1)$

3. Enzyme digestion buffer

$0.3 \%$ pectolyase $\mathrm{Y} 23,1.5 \mathrm{mg}(0.0015 \mathrm{~g})$

$0.3 \%$ cellulase, $1.5 \mathrm{mg}(0.0015 \mathrm{~g})$

$1.4 \%$ $\beta$-glucoronidase, $7.5 \mathrm{mg}(0.0075 \mathrm{~g})$

$6 \%$ sucrose, $30 \mathrm{mg}(0.03 \mathrm{~g})$

First dissolve enzymes in $10 \mathrm{mM}$ sodium citrate $(100 \mu \mathrm{l})$, and then continue to add sodium citrate up to $500 \mu \mathrm{l}$. This solution can be stored for up to one month at $-20^{\circ} \mathrm{C}$.

4. FISH Buffer $(500 \mu \mathrm{l})$

$10 \%$ formamide (add $50 \mu \mathrm{l} 100 \%$ formamide)

2x SSC (add $50 \mu \mathrm{l} 20 x$ SSC)

$10 \%$ dextran sulfate (add $100 \mu \mathrm{l} 50 \%$ dextran sulfate, which is prepared by simply dissolving $1 \mathrm{~g}$ of dextran sulfate powder in $2 \mathrm{ml}$ of distilled water, then heat to $80{ }^{\circ} \mathrm{C}$ to improve mixing)

Salmon sperm blocking DNA (add $75 \mu \mathrm{l}$ of $25 x$ sperm, final concentration: $250 \mu \mathrm{g} / \mu \mathrm{l}$ )

In order to prepare $25 x$ salmon sperm DNA $(25 \mu \mathrm{g} / \mu \mathrm{l})$, dissolve $250 \mathrm{mg}$ sperm powder into $1 \mathrm{ml}$ of distilled water or $1 \mathrm{x}$ PBS

Keep at $-20{ }^{\circ} \mathrm{C}$

$0.1 \%$ SDS (add $5 \mu$ l of $10 \%$ SDS)

Distilled water, $220 \mu \mathrm{l}$

5. 10x phosphate buffered saline (PBS)

Prepare $\mathrm{NaCl}, 80 \mathrm{~g} ; \mathrm{KCl}, 2 \mathrm{~g}$; $\mathrm{Na}_{2} \mathrm{HPO}_{4} \cdot 7 \mathrm{H}_{2} \mathrm{O}, 14.4 \mathrm{~g} ; \mathrm{KH}_{2} \mathrm{PO}_{4}, 2.4 \mathrm{~g} ; \mathrm{ddH}_{2} \mathrm{O}$ up to 1,000 $\mathrm{ml}$

Adjust $\mathrm{pH}$ to $7.2-7.6$

Autoclave

6. $20 \times \mathrm{SSC}$

Prepare $\mathrm{NaCl}, 175.3 \mathrm{~g}(3 \mathrm{M})$, and sodium citrate dihydrate $88.2 \mathrm{~g}(300 \mathrm{mM})$, then dissolved in $800 \mathrm{ml}$ of water 
Adjust $\mathrm{pH}$ to 7.0

Take volume to $1,000 \mathrm{ml}$

Autoclave

\section{Acknowledgments}

This work was supported by research grants from Academia Sinica (Taiwan), the National Science and Technology Program for Agricultural Biotechnology (NSTP/AB, 098S0030055-AA), Taiwan, and the National Science Council (NSF; 99-2321-B-001-036-MY3), Taiwan, to G.-Y. Jauh; an NSF grant (MCB0718191) to C. A. Makaroff, and a study-abroad contract from the University of Costa Rica to P. Bolaños-Villegas.

\section{References}

1. Bolaños-Villegas, P., Yang, X., Wang, H. J., Juan, C. T., Chuang, M. H., Makaroff, C. A. and Jauh, G. Y. (2013). Arabidopsis CHROMOSOME TRANSMISSION FIDELITY 7 (AtCTF7/ECO1) is required for DNA repair, mitosis and meiosis. Plant J 75(6): 927-9.

2. Yang, X., Boateng, K. A., Yuan, L., Wu, S., Baskin, T. I. and Makaroff, C. A. (2011). The radially swollen 4 separase mutation of Arabidopsis thaliana blocks chromosome disjunction and disrupts the radial microtubule system in meiocytes. PLoS One 6(4): e19459. 